\title{
A STUDY OF ABDOMINAL SURGICAL EMERGENCIES IN GERIATRIC PATIENTS
}

\author{
Neha Suhas Sawant ${ }^{1}$, M. B. Bagwan ${ }^{2}$
}

1Resident, Department of General Surgery, Krishna Institute of Medical Sciences, Karad, Maharashtra, India. ${ }^{2}$ Associate Professor, Department of General Surgery, Krishna Institute of Medical Sciences, Karad, Maharashtra, India.

\section{ABSTRACT}

\section{BACKGROUND}

Emergency surgery is defined as non-elective surgery that is performed with the aim to prevent morbidity or fatal health consequences of a surgically treatable disease. ${ }^{1,2}$

Aims and Objectives-

- To study and analyse the abdominal surgical emergencies in geriatric patients.

- To assess the types of abdominal surgical emergencies that occur in geriatric age group of 60 and above.

- To assess the type of surgical intervention done.

- To study the complications faced in this group undergoing surgical intervention.

\section{MATERIALS AND METHODS}

In this observational study, 113 patients were admitted from Dec. 2015 to May 2017 undergoing surgical intervention within 12 hours. Already diagnosed, conserved and post-operative cases referred to our hospitals were excluded.

\section{RESULTS}

$82 \%$ of the patients were from age group 60 - 70 years, where 64 were male and 36 were female patients in the study. There is a significant association between sex and comorbidities ( $p=0.001$ ), where $19 \%$ of males and $12 \%$ of females have hypertension followed by $18 \%$ of males and $9 \%$ of females having diabetes mellitus, suggesting male patients having more chances of having comorbidities. The proportion of patients having hypertension and diabetes is significantly higher than other comorbidities, i.e. $31 \%$ cases suffered from hypertension followed by $27 \%$ cases suffering from diabetes mellitus. By applying Z-test of difference between two proportions, the proportion of comorbidities of hypertension and diabetes is significantly higher than other comorbidities ( $\mathrm{p}<0.01$ ), i.e. $31 \%$ cases suffered from hypertension followed by $27 \%$ cases suffering from diabetes mellitus. The most common symptom in the study population was Pain (71\%). Others were Vomiting (15\%), Constipation (7\%), Melena (2\%) and Fever (5\%). By applying Z-test of difference between two proportions, the proportion of symptom of pain and vomiting is significantly higher, i.e. $71 \%$ cases and $15 \%$ cases respectively $(\mathrm{p}<0.01)$. Many $(69 \%)$ of the cases had sign of tenderness followed by $19 \%$ of the patients having absent peristalsis. By applying Z-test of difference between two proportions, the proportion of tenderness is significantly higher $(p<0.01)$. X-ray abdomen erect was done in $52 \%$ of the cases. In majority $(52 \%)$ cases, ultrasonography of abdomen and pelvis was done. Closure of perforation (26\%) was the most common procedure done followed by Adhesiolysis (17\%) and Resection and Anastomosis (10\%). In rest of the patients, other procedures were performed. Open Appendicectomy (18\%), Liver Suturing, Open Cholecystectomy (10\%) and Splenectomy (9\%). By applying Z-test of difference between two proportions, the proportion of procedure closure of perforation is significantly higher $(p<0.01)$. In this study, maximum (28\%) surgical emergencies were of intestinal perforation followed by intestinal obstruction (25\%) and appendicitis (18\%). Others were Spleen Injury (9\%), Liver Injury (10\%) and Cholelithiasis with Cholecystitis (10\%). By applying Z-test of difference between two proportions, the proportion of intestinal perforation was significantly higher $(\mathrm{p}<0.001)$ than other surgical emergencies. Sepsis was the most common (39\%) complication followed by Suture Line Infection (24\%), Respiratory Distress (14\%) and Bleeding (3\%). 20\% of the patients had no complications. By applying Z-test of difference between two proportions, the proportion of post-operative complications of sepsis is significantly higher than other complications, ( $p<0.01) .13$ patients out of the total 100 in the study had expired. In the study population, 79\% cases had deranged albumin, deranged renal function tests were found in $73 \%$ of the cases, $60 \%$ patients stayed in the hospital for more than 15 days, 76 patients had hyperglycaemia i.e. random blood sugar level more than $180 \mathrm{mg} / \mathrm{dL}, 76 \%$ patients were anaemic i.e. haemoglobin below $11 \mathrm{~g} / \mathrm{dL}$. There is a significant association between RFT and post-operative complications $(p=0.042)$, suggesting patients with deranged RFT had higher rates of post-operative complications. There is a significant association between albumin and post-operative complications ( $p=0.02)$, suggesting patients with deranged serum albumin levels had higher rates of post-operative complications. There is a significant association between electrolyte imbalance and post-operative complications $(\mathrm{p}=0.043)$. Complications were seen commonly in patients with Electrolyte imbalance. There is no any significant association between duration of stay and postoperative complications ( $\mathrm{p}=0.125$ ), suggesting in our study population duration of stay did not have any effect on post-operative complications. There is no any significant association between haemoglobin levels and post-operative complications ( $p=0.197$ ), suggesting in our study population haemoglobin levels did not have any effect on post-operative complications. There is a significant association between RBS and post-operative complications $(\mathrm{p}=0.014)$. The number of patients with post-operative complications were more with increased RBS (> $180 \mathrm{mg} / \mathrm{dL})$.

\section{CONCLUSION}

This study has helped us in providing better clinical, diagnostic and management criteria to reduce mortality among geriatric age group which are usually neglected. 


\section{KEY WORDS}

Abdominal Surgical Emergencies, Geriatric, Comorbidities, Haemoperitoneum, Intestinal Perforation, Intestinal Obstruction, Resection Anastomosis, Adhesiolysis.

HOW TO CITE THIS ARTICLE: Sawant NS, Bagwan MB. A study of abdominal surgical emergencies in geriatric patients. J. Evolution Med. Dent. Sci. 2018;7(24):2889-2895, DOI: 10.14260/jemds/2018/651

\section{BACKGROUND}

Emergency surgery is defined as non-elective surgery that is performed with an aim to prevent morbid or fatal health consequences of a surgically treatable disease. ${ }^{1,2}$

Emergency surgical presentation is one such situation where surgeon is faced with therapeutic dilemma. On the one hand it is clear that most of these patients may have a limited life expectancy, while on the other hand surgical intervention appears to be unavoidable in these circumstances.

Emergency abdominal surgery patients who develop post-operative complications are more likely to be older, male, smokers, alcoholics with increased perioperative blood glucose, creatinine levels and lower serum albumin levels. ${ }^{3}$ They consume tremendous amount of medical resources requiring laboratory testing, imaging and the consultant services at significantly higher rate than younger patients.

The most common emergency abdominal surgical presentation is bowel obstruction, appendicitis, perforative peritonitis and bleeding, splenic injury, liver injury, obstructed hernia, cholecystitis and malignancy.

\section{Aim}

To study and analyse the abdominal surgical emergencies in geriatric patients.

\section{Objectives}

- To assess the types of abdominal surgical emergencies that occur in geriatric age group of 60 and above.

- To assess the type of surgical intervention done.

- To study the complications faced in this group undergoing surgical intervention.

\section{MATERIALS AND METHODS}

In this observational study, the source of data is all the patients having abdominal surgical emergencies admitted in our tertiary centre during the period of Dec. 2015 to May 2017. A total of 113 patients were admitted in our tertiary centre with abdominal surgical emergencies.

\section{Inclusion Criteria}

1. Age group of 60 and above involving both sexes undergoing surgical intervention within $12 \mathrm{hrs}$.

2. Cases will be included according to the definition illustrated in the Sabiston Textbook of Surgery, Bailey and Love.

'Financial or Other Competing Interest': None.

Submission 01-05-2018, Peer Review 25-05-2018,

Acceptance 01-06-2018, Published 11-06-2018.

Corresponding Author:

Dr. M. B. Bagwan,

Associate Professor,

Department of General Surgery,

Krishna Institute of Medical Sciences,

Karad, Maharashtra, India.

E-mail: neha2924vn@gmail.com

DOI: $10.14260 /$ jemds $/ 2018 / 651$

(c) $(1)(-)$

\section{Exclusion Criteria}

1. Already diagnosed and conserved cases, which may be referred to our hospital for further management.

2. Post-operative cases referred for further management.

3. Patients undergoing conservative management.

RESULTS

\begin{tabular}{|c|c|c|}
\hline Age in Years & No. of Cases & Percentage (\%) \\
\hline $60-70$ & 82 & $82 \%$ \\
\hline $70-80$ & 15 & $15 \%$ \\
\hline$>80$ & 3 & $3 \%$ \\
\hline Total & $\mathbf{1 0 0}$ & $\mathbf{1 0 0} \%$ \\
\hline Mean \pm SD & 67.25 years \pm 9.94 years \\
\hline \multicolumn{3}{|c|}{ Table 1. Age Distribution } \\
\hline
\end{tabular}

Maximum (82\%) of the patients were from age group 60 70 years.

\begin{tabular}{|c|c|c|}
\hline Male & Female & Total \\
\hline No. (\%) & No. (\%) & No. (\%) \\
\hline $64(64 \%)$ & $36(36 \%)$ & $100(100 \%)$ \\
\hline \multicolumn{3}{|c|}{ Male: Female ratio= 1: 0.56 } \\
\hline \multicolumn{3}{|c|}{ Table 2. Sex Distribution } \\
\hline
\end{tabular}

There were 64 male and 36 female patients in the study.

\begin{tabular}{|c|c|c|c|}
\hline Comorbidities & Male & Female & Total \\
\hline Hypertension & 19 & 12 & 31 \\
\hline Diabetes mellitus & 18 & 9 & 27 \\
\hline $\begin{array}{c}\text { Ischaemic heart } \\
\text { disease }\end{array}$ & 3 & 3 & 6 \\
\hline TB & 3 & 2 & 5 \\
\hline Nil & 21 & 10 & 31 \\
\hline Total & $\mathbf{6 4 ( 6 4 \% )}$ & $\mathbf{3 6 ( 3 6 \% )}$ & $\mathbf{1 0 0 ( 1 0 0 \% )}$ \\
\hline \multicolumn{4}{|c}{ Table 3. Sex and Comorbidities } \\
\end{tabular}

Value of $\chi^{2}=23.546, p=0.001$, significant.

There is a significant association between sex and comorbidities $(\mathrm{p}=0.001)$, where $19 \%$ of males and $12 \%$ of females have hypertension followed by $18 \%$ of males and $9 \%$ of females having diabetes mellitus, suggesting male patients having more chances of having comorbidities.

\begin{tabular}{|c|c|c|}
\hline Comorbidities & No. of Cases & Percentage (\%) \\
\hline Hypertension & 31 & $31 \%$ \\
\hline Diabetes mellitus & 27 & $27 \%$ \\
\hline Ischaemic Heart Disease & 6 & $6 \%$ \\
\hline TB & 5 & $5 \%$ \\
\hline Nil & 31 & $31 \%$ \\
\hline Total & $\mathbf{1 0 0}$ & $\mathbf{1 0 0 \%}$ \\
\hline \multicolumn{2}{|c|}{ Table 4. Comorbidities } \\
\hline
\end{tabular}

The proportion of patients having hypertension and diabetes is significantly higher than other comorbidities, i.e. $31 \%$ cases suffered from hypertension followed by $27 \%$ cases suffering from diabetes mellitus. Other comorbidities found were IHD (6\%) and TB (5\%). 31\% of the patients did not have any comorbidities.

By applying Z-test of difference between two proportions, the proportion of comorbidities hypertension and diabetes is 
significantly higher than other comorbidities $(\mathrm{p}<0.01)$, i.e $31 \%$ cases suffered from hypertension followed by $27 \%$ cases suffering from diabetes mellitus.

\begin{tabular}{|c|c|c|}
\hline Symptoms & No. of Cases & Percentage (\%) \\
\hline Pain & 71 & $71 \%$ \\
\hline Vomiting & 15 & $15 \%$ \\
\hline Constipation & 7 & $7 \%$ \\
\hline Melena & 2 & $2 \%$ \\
\hline Fever Table 5. Symptoms \\
\hline \multicolumn{2}{|c}{} \\
\hline
\end{tabular}

The most common symptom in the study population was Pain (71\%), others were Vomiting (15\%), Constipation (7\%), Melena (2\%) and Fever (5\%).

By applying Z-test of difference between two proportions the proportion of symptom pain and vomiting is significantly higher, i.e. $71 \%$ cases and $15 \%$ cases respectively $(p<0.01)$.

\begin{tabular}{|c|c|c|}
\hline Signs & No. of Cases & Percentage (\%) \\
\hline Tenderness & 69 & $69 \%$ \\
\hline Distension & 17 & $17 \%$ \\
\hline Guarding & 12 & $12 \%$ \\
\hline Rigidity & 11 & $11 \%$ \\
\hline Absent peristalsis & 19 & $19 \%$ \\
\hline Lump & 5 & $5 \%$ \\
\hline \multicolumn{2}{|c}{ Table 6. Signs } \\
\hline
\end{tabular}

Many (69\%) of the cases had sign of tenderness followed by $17 \%$ cases having distension. Other signs were guarding (12\%), rigidity (11\%) and lump (5\%). $19 \%$ of the patients had absent peristalsis.

By applying Z-test of difference between two proportions, the proportion of sign of tenderness is significantly higher, ( $\mathrm{p}<0.01$ ). 69\% cases had tenderness followed by $19 \%$ cases having absent peristalsis.

\begin{tabular}{|c|c|c|}
\hline & No. of Cases & Percentage (\%) \\
\hline Yes & 52 & $52 \%$ \\
\hline No & 48 & $48 \%$ \\
\hline Total & $\mathbf{1 0 0}$ & $\mathbf{1 0 0 \%}$ \\
\hline \multicolumn{2}{|c|}{ Table 7. X-Ray Abdomen Erect } \\
\hline
\end{tabular}

X-ray abdomen erect was done in $52 \%$ of the cases.

\begin{tabular}{|c|c|c|}
\hline & No. of Cases & Percentage (\%) \\
\hline Yes & 52 & $52 \%$ \\
\hline No & 48 & $48 \%$ \\
\hline Total & $\mathbf{1 0 0}$ & $\mathbf{1 0 0 \%}$ \\
\hline Table 8. USG of Abdomen and Pelvis \\
\hline
\end{tabular}

In majority (52\%) cases, ultrasonography of abdomen and pelvis was done.

\begin{tabular}{|c|c|c|}
\hline Procedure & No. of Cases & Percentage (\%) \\
\hline Closure of perforation & 26 & $26 \%$ \\
\hline Open cholecystectomy & 10 & $10 \%$ \\
\hline Splenectomy & 9 & $9 \%$ \\
\hline Liver suturing & 10 & $10 \%$ \\
\hline Open appendicectomy & 18 & $18 \%$ \\
\hline Adhesiolysis & 17 & $17 \%$ \\
\hline Resection anastomosis & 10 & $10 \%$ \\
\hline Total Table 9. Procedure \\
\hline \multicolumn{2}{|c|}{} \\
\hline
\end{tabular}

Closure of perforation (26\%) was the most common procedure done followed by Adhesiolysis (17\%) and Resection Anastomosis (10\%). In rest of the patients other procedures were performed like- Open Appendicectomy (18\%), Liver Suturing, Open Cholecystectomy (10\%) and Splenectomy (9\%).

By applying Z-test of difference between two proportions, the proportion of procedure closure of perforation is significantly higher, i.e. $26 \%$ cases ( $p<0.01$ ).

\begin{tabular}{|c|c|c|}
\hline Diagnosis & No. of Cases & Percentage (\%) \\
\hline Intestinal Obstruction (IO) & 25 & $25 \%$ \\
\hline Intestinal Perforation (IP) & 28 & $28 \%$ \\
\hline Appendicitis (A) & 18 & $18 \%$ \\
\hline Spleen Injury (SI) & 9 & $9 \%$ \\
\hline Liver Injury (LI) & 10 & $10 \%$ \\
\hline $\begin{array}{c}\text { Cholelithiasis with } \\
\text { Cholecystitis (CC) }\end{array}$ & 10 & $10 \%$ \\
\hline \multicolumn{2}{|c|}{ Total Table 10. Diagnosis } \\
\hline \multicolumn{2}{|c|}{} \\
\hline
\end{tabular}

In this study, maximum (28\%) surgical emergencies were of Intestinal Perforation followed by Intestinal Obstruction (25\%) and Appendicitis (18\%). Others were Spleen Injury (9\%), Liver Injury (10\%) and Cholelithiasis with Cholecystitis (10\%).

By applying Z-test of difference between two proportions, the proportion of Intestinal Perforation was significantly higher $(\mathrm{p}<0.001)$ than other surgical emergencies.

\begin{tabular}{|c|c|c|}
\hline $\begin{array}{c}\text { Post-Operative } \\
\text { Complications }\end{array}$ & No. of Cases & Percentage (\%) \\
\hline Bleeding & 3 & $3 \%$ \\
\hline Sepsis & 39 & $39 \%$ \\
\hline Suture line infection & 24 & $24 \%$ \\
\hline Respiratory distress & 14 & $14 \%$ \\
\hline No complications & 20 & $20 \%$ \\
\hline Total & 100 & $100 \%$ \\
\hline
\end{tabular}

Sepsis was the most common (39\%) complication, followed by Suture Line Infection (24\%), Respiratory Distress (14\%) and Bleeding (3\%). 20\% of the patients had no any complications. By applying Z-test of difference between two proportions, the proportion of post-operative complications of sepsis (39\%) is significantly higher than other complications $(\mathrm{p}<0.01)$.

\begin{tabular}{|c|c|c|}
\hline Outcome & No. of Cases & Percentage (\%) \\
\hline Expired & 13 & $13 \%$ \\
\hline Alive Table 12. Outcome \\
\hline \multicolumn{2}{|c|}{} \\
\hline
\end{tabular}

13 patients out of the total 100 in the study had expired.

\begin{tabular}{|c|c|c|}
\hline Albumin & No. of Cases & Percentage (\%) \\
\hline Deranged & 79 & $79 \%$ \\
\hline Normal & 21 & $21 \%$ \\
\hline \multicolumn{3}{|c|}{ Table 13. Albumin } \\
\hline
\end{tabular}

In the study population, $79 \%$ cases had deranged albumin. 


\begin{tabular}{|c|c|c|}
\hline RFT & No. of Cases & Percentage (\%) \\
\hline Deranged & 73 & $73 \%$ \\
\hline Normal & 27 & $27 \%$ \\
\hline \multicolumn{3}{|c|}{ Table 14. RFT } \\
\hline
\end{tabular}

In our study, deranged renal function tests were found in $73 \%$ of the cases.

\begin{tabular}{|c|c|c|}
\hline Hospital Stay & No. of Cases & Percentage (\%) \\
\hline More than 15 days & 60 & $60 \%$ \\
\hline Less than 15 days & 40 & $40 \%$ \\
\hline \multicolumn{2}{|c|}{ Table 15. Hospital Stay } \\
\hline
\end{tabular}

In the study, $60 \%$ patients stayed in the hospital for more than 15 days.

\begin{tabular}{|c|c|c|}
\hline RBS & No. of Cases & $\begin{array}{c}\text { Percentage } \\
\text { (\%) }\end{array}$ \\
\hline$>180 \mathrm{mg} / \mathrm{dL}$ & 76 & $76 \%$ \\
\hline$<180 \mathrm{mg} / \mathrm{dL}$ & 24 & $24 \%$ \\
\hline \multicolumn{2}{|c|}{ Table 16. $\mathrm{RBS}$} \\
\hline
\end{tabular}

In the study 76 patients had hyperglycaemia, i.e. random blood sugar level more than $180 \mathrm{mg} / \mathrm{dL}$.

\begin{tabular}{|c|c|c|}
\hline $\begin{array}{c}\text { Haemoglobin } \\
\text { Concentration }\end{array}$ & No. of Cases & Percentage (\%) \\
\hline$<11 \mathrm{~g} / \mathrm{dL}$ & 76 & $76 \%$ \\
\hline$>11 \mathrm{~g} / \mathrm{dL}$ & 24 & $24 \%$ \\
\hline \multicolumn{2}{|c|}{ Table 17. Haemoglobin Concentration } \\
\hline
\end{tabular}

In our study $76 \%$ patients were anaemic, i.e. haemoglobin below $11 \mathrm{~g} / \mathrm{dL}$.

\begin{tabular}{|c|c|c|c|}
\hline \multirow{2}{*}{$\begin{array}{c}\text { Post-Operative } \\
\text { Complications }\end{array}$} & \multicolumn{3}{|c|}{ RFTs } \\
\cline { 2 - 4 } & Deranged & Normal & Total \\
\hline Complications Present & 62 & 18 & 80 \\
\hline No Complications & 11 & 9 & 20 \\
\hline Total & 73 & 27 & 100 \\
\hline Value of $\chi^{2}=4.11, \mathrm{p}=0.042$, Significant \\
\hline Table 18. RFT and Post-Operative Complications \\
\hline
\end{tabular}

There is a significant association between RFT and postoperative complications $(\mathrm{p}=0.042)$, Suggesting patients with deranged RFT had higher rates of post-operative complications.

\begin{tabular}{|c|c|c|c|}
\hline \multirow{2}{*}{$\begin{array}{l}\text { Post-Operative } \\
\text { Complications }\end{array}$} & \multicolumn{3}{|c|}{ Albumin } \\
\hline & Deranged & Normal & Total \\
\hline Complications Present & 67 & 13 & 80 \\
\hline No Complications & 12 & 8 & 20 \\
\hline Total & 79 & 21 & 100 \\
\hline \multicolumn{4}{|c|}{ Value of $\chi^{2}=5.44, p=0.02$, Significant } \\
\hline
\end{tabular}

There is a significant association between Albumin and post-operative complications $(\mathrm{p}=0.02)$, suggesting patients with deranged serum albumin levels had higher rates of postoperative complications.

\begin{tabular}{|c|c|c|c|}
\hline \multirow{2}{*}{$\begin{array}{c}\text { Post-Operative } \\
\text { Complications }\end{array}$} & \multicolumn{3}{|c|}{ Electrolytes } \\
\cline { 2 - 4 } & Deranged & Normal & Total \\
\hline Complications Present & 65 & 15 & 80 \\
\hline No Complications & 12 & 8 & 20 \\
\hline Total & 77 & 23 & 100 \\
\hline \multicolumn{2}{|c|}{ Value of $\chi^{2}=4.08, \mathrm{p}=0.043$, Significant } \\
\hline Table 20. Electrolytes and Post-Operative Complications \\
\hline
\end{tabular}

There is a significant association between Electrolyte imbalance and post-operative complications $(p=0.043)$ Complications were seen commonly in patients with Electrolyte imbalance.

\begin{tabular}{|c|c|c|c|}
\hline \multirow{2}{*}{$\begin{array}{c}\text { Post-Operative } \\
\text { Complications }\end{array}$} & \multicolumn{3}{|c|}{ Duration of Stay } \\
\cline { 2 - 4 } & $\mathbf{> 1 5}$ days & $<\mathbf{1 5}$ days & Total \\
\hline Complications Present & 51 & 29 & 80 \\
\hline No Complications & 9 & 11 & 20 \\
\hline Total & 60 & 40 & 100 \\
\hline Value of $\chi^{2}=2.34, \mathrm{p}=0.125$, Not Significant \\
\hline Table 21. Duration of Stay and Post-Operative \\
Complications \\
\hline
\end{tabular}

There is no any significant association between duration of stay and post-operative complications ( $p=0.125)$, suggesting in our study population duration of stay did not have any effect on post-operative complications.

\begin{tabular}{|c|c|c|c|}
\hline \multirow{2}{*}{$\begin{array}{l}\text { Post-Operative } \\
\text { Complications }\end{array}$} & \multicolumn{3}{|c|}{ Duration of Stay } \\
\hline & $<11 \mathrm{~g} / \mathrm{dL}$ & $<15$ days & Total \\
\hline Complications Present & 63 & 17 & 80 \\
\hline No Complications & 13 & 7 & 20 \\
\hline Total & 76 & 24 & 100 \\
\hline \multicolumn{4}{|c|}{ Value of $\chi^{2}=1.66, p=0.197$, Not Significant } \\
\hline & omplicat & $D_{0}$ & \\
\hline
\end{tabular}

There is no any significant association between Haemoglobin levels and post-operative complications $(\mathrm{p}=0.197)$, suggesting in our study population haemoglobin levels did not have any effect on post-operative complications.

\begin{tabular}{|c|c|c|c|}
\hline \multirow{2}{*}{$\begin{array}{c}\text { Post-Operative } \\
\text { Complications }\end{array}$} & \multicolumn{3}{|c|}{ RBS } \\
\cline { 2 - 4 } & $\mathbf{> 1 8 0}$ & $\mathbf{< 1 8 0}$ & Total \\
\hline Complications Present & 65 & 15 & 80 \\
\hline No Complications & 11 & 9 & 20 \\
\hline Total & 76 & 24 & 100 \\
\hline Value of $\chi^{2}=6.04, \mathrm{p}=0.014$, Significant \\
\hline \multicolumn{2}{|c|}{ Table 23. RBS and Post-Operative Complications } \\
\hline
\end{tabular}

There is a significant association between RBS and postoperative complications $(\mathrm{p}=0.014)$, number of patients with post-operative complications were more with increased RBS $(>180 \mathrm{mg} / \mathrm{dL})$.

\section{DISCUSSION}

In our observational study 113 patients were analysed, of which 13 patients did not follow-up. Therefore, among the 100 patients 64 were male and 36 were female patients. In Akinbami et al, $42 \%$ were male and $58 \%$ were female.

The patients in our study who underwent emergency abdominal surgery were Open Appendicectomy (18\%), 
Resection Anastomosis (10\%), Adhesiolysis (17\%), Closure of Perforation (26\%) and Open Cholecystectomy (10\%).

Maximum cases were Intestinal Perforation (28\%) followed by Intestinal Obstruction (25\%), which occurred in the geriatric patients, $\mathrm{p}<0.001$, by applying Z-test of difference between the two proportions. Post-operative complications in our study were identified in $80 \%$ as compared to $29 \%$ patients, $\mathrm{p}<0.01$ by applying Z-test.

Most common post-operative complications in our study were sepsis (39\%) followed by suture line infection (24\%), where $\mathrm{p}<0.01$ by applying Z-test of difference between the two proportions. 30 days mortalities in our study were $13 \%$ compared to Akinbami et al 73 (8.9\%).

Among the patients considered in our study, the maximum incidence of abdominal surgical emergencies among males as compared to females are being highest in the age group between 60 and 70 years. $82 \%$ of patients who underwent emergency surgery were majority between 60 and 70 years, males (54\%) undergoing intervention more frequently than females (28\%).

In our study, 31\% had hypertension followed by DM type $2(27 \%)$, where $\mathrm{p}<0.01$ by applying Z-test.

In our study, highest incidences of comorbidities are more common in the males (64\%) than in females (36\%) $\mathrm{p}=0.001$. Chi-square value is 23.546 .

In our study the most common symptom was pain (71\%) followed by vomiting (15\%), where $\mathrm{p}<0.01$ by applying Ztest.

In our study, the most common sign was tenderness (69\%) followed by absent peristalsis (19\%). In a study conducted by Sawyers JJ et al, tenderness was $88 \%{ }^{4} 52 \%$ of patients had done x-ray abdomen erect.

Patients who underwent emergency abdominal surgery, post-operative complications were more in males than in females. So morbidity seen in our study is more in males. The cause in still unknown. ${ }^{5}$

Hyperglycaemia is known to have deleterious effect on wound healing. In our study random blood sugar of more than $180(76 \%)$ have post-operative complications with pvalue $=0.014$ and chi-square value is $\chi^{2}=6.04$. So there is higher association between hyperglycaemia and postoperative complications, as it delays healing of wound. Normal level of random blood sugar level is less than 180 $\mathrm{mg} / \mathrm{dL}$, so good glycaemic control reduces the post-operative complications.

Increased blood urea when blood urea level more than 45 $\mathrm{mg} / \mathrm{dL}$ and serum creatinine level more than $1.4 \mathrm{mg} / \mathrm{dL}$ is called increased serum creatinine level.

$73 \%$ cases had deranged renal function test, out of which $62 \%$ of patients were prone to post-operative complications. $\mathrm{P}$-value $=0.042$ and Chi-square value is $\chi^{2}=4.11$, significant.

So, there is higher association between RFT and postoperative complications. Increased blood urea level found in our study was possibly due to hypovolaemia, so patients may be benefited by adequate intravenous fluid resuscitation which reduces the post-operative complications.

In our study we had 79 patients with deranged albumin levels, out of which 67 patients developed post-operative complications. Therefore, in decreased serum albumin there is higher association with post-operative complications ( $p$ value $=0.02$ ), chi-square value is 5.44. In Golub's et al serum albumin level, less than 3 have higher post-operative complications. By giving intravenous supplementation of albumin or oral supplementation of protein the patient will improve post-operatively. ${ }^{6}$

77 patients had deranged electrolytes, out of which 65 patients developed post-operative complications, so deranged electrolytes has a significant association with postoperative complications, $p=0.043$, chi-square value is 4.08 , significant.

Duration of procedure also increases the post-operative complications. Finally, composition of surgical team that is taking care of emergency abdominal surgery may be modified. ${ }^{1}$ Recent support for acute care surgeons who address both trauma and emergent general surgery is an avenue that needs to be explored more rigorously. Such acute care surgeons may be able to potentially decrease the length of surgery and delay the surgery through their expertise. ${ }^{7}$

Duration of stay is also increased due to post-op complications. Although, in our study there were 60 patients who stayed for more than 15 days. Among these 60 patients, 51 patients had developed post-operative complications. There was no any significant association found between duration of stay and post-operative complication, $\mathrm{p}=0.125$, chi-square value $=2.34$.

Anaemia is defined as haemoglobin percentage less than $11 \mathrm{gm} / \mathrm{dL} .{ }^{1}$ Lower the haemoglobin percentage has higher post-operative complication. Although, in our study 63 patients were anaemic who developed post-operative complications, but this association was not significant in our study, $\mathrm{p}=0.197$, chi-square test is $\chi^{2}=1.66$, not significant.

Considerable progress has been made in surgical techniques, anaesthesia procedures and post-operative patient's care in terms of the results of surgical operation in the geriatric population. Surgery remains a major cause of morbidity and mortality in elderly people due to their depleted physiologic reserves.

In an effort to decrease mortality rates, precautions should be taken beforehand particularly to avoid complications observed in geriatric patients considering the high mortality rates observed in late stage complications. For instance elderly patients with common conditions such as acute cholecystitis incarcerated hernia can be offered elective surgery to avoid emergency intervention. Keeping systematic disease under control will render surgical operations safer. Britt et al developed an acute care surgery model to decrease time delays to surgery by using daytime operating rooms and the experience of the surgeons to improve medical decision making. 8

Earley et al examined effects of this model on outcomes of patients undergoing appendectomies and found decreased time for surgery, complication rate and length of stay. ${ }^{7}$

Approximately, $10 \%$ of civilian injuries that require operation are the result of abdominal trauma. ${ }^{9}$ Unrecognised injury to intra-abdominal contents remains a distressingly frequent cause of preventable death. ${ }^{10,11,12}$ As many as onethird of patients with an initial benign abdominal examination will require emergency laparotomy. ${ }^{12}$

The appropriate management of abdominal trauma depends on a careful initial evaluation, the timely use of diagnostic procedures and vigorous therapy directed at the decision to perform laparotomy for abdominal trauma is far more complex, because structural injury is less obvious and 
associated multisystem trauma may demand more urgent operation.

\section{Diagnostic Aids}

Rob's dictum ${ }^{13}$ (1947)- 'The absence of peristaltic sounds, confirmed and reconfirmed is a positive indication for laparotomy, but the presence of peristaltic sound is only a valuable guide towards and not a positive indication for conservative management.'

\section{Haemoglobin Percentage (Hb\%)}

Haemoglobin percentage is one of the most important laboratory investigation available in evaluation of the patient with abdominal trauma.

In this study, routine $\mathrm{Hb} \%$ estimation was done in all cases.

\section{Blood Group}

In order to give blood transfusion whenever necessary for resuscitation, blood grouping was done.

\section{Ill. Urine Examination}

Urine, routine and microscopic examination was carried out in all cases. This is important in the patients with urinary tract injury to rule out microscopic haematuria.

\section{Blood Sugar}

Blood sugar was done in all patients to check for diabetes mellitus.

\section{Blood Urea Nitrogen and Serum Creatinine}

Serum urea and Serum creatinine was done in all patients to know renal function.

\section{X-Ray Abdomen in Erect Position}

X-Ray Abdomen in Erect Position looked for-

a. Free intraperitoneal air (intestinal perforation).

b. Ground glass appearance.

c. Multiple gas and fluid levels.

d. Increased radiodensity in right or left hypochondrium.

\section{X-Ray Chest}

X-ray chest in erect position looked for-

- Free intraperitoneal air (intestinal perforation).

- Injury to diaphragm.

\section{Resuscitative Measures}

1. Maintenance of Patent Airway: This was especially important in patients of hemoperitoneum with either head injury or chest injury. Maintenance of airway and thorough suction of oropharynx was done. An emergency tracheostomy was done in these patients when respiration was poor.

2. Restoration of Plasma Volume: This was done with Ringer's lactate solution, dextran and cross-matched blood. An indwelling catheter was introduced to monitor the urine output.

3. Oxygen Therapy: Patients in shock were put on venti mask with oxygen flow of 5 litres/min.

4. Position of Patient: A head low position was given for patients in shock to increase the venous return to the heart.
In severe chest injuries and head injuries, only legs up position was given to avoid respiratory embarrassment through congestion or cerebral oedema.

5. Keeping the Body Warm: We would like to stress that this was not often given enough attention. A simple woolen blanket was all that was necessary to minimise the deleterious effects of shock.

\section{Conservative Management}

It has been observed that some patients with intra-abdominal injury do not need laparotomy and can be treated conservatively. Conservative line of treatment was followed as under-

\section{a. Nil by Mouth-}

The patient is not allowed to take anything orally. This helps for two ways. Firstly, it prevents soiling of the peritoneal cavity in perforated viscous and secondly it also prevents the risk of aspiration due to regurgitation during induction of anaesthesia or recovery from anaesthesia.

\section{b. IV Fluids-}

This helps to supply the daily requirement of fluid electrolytes and calories in patients with nasogastric suction and nil by mouth patients. Fluids are administered according to the severity of the case.

\section{c. Ryle's Tube Aspiration-}

This is done to prevent soiling of the peritoneal cavity in perforated viscous by gastric juices. This is done continuously and 2 hourly, so that the stomach is kept empty. A deflated abdomen aids respiration by reducing respiratory embarrassment

\section{d. IV Antibiotics-}

Prophylactic antibiotics were used in all surgical cases. Cefotaxime, Metronidazole and Piperacillin Tazobactam are the most commonly used antibiotics here. The need for antibiotics in patients with penetrating abdominal wound is clear, but the choice of antibiotics, the dosage and duration of administration remains controversial-

a. Pulse rate and blood pressure monitoring every two hourly.

b. Abdominal girth record two hourly.

c. Input and output record.

During the conservative line of treatment reliance was on pulse rate, blood pressure, temperature and pain in abdomen. When there was deterioration of vital signs, patients were subjected for surgical intervention.

\section{CONCLUSION}

During this study, all the abdominal surgical emergencies were performed on geriatric group. All patients in this study had undergone surgical intervention. This study has helped us to provide better clinical diagnostic and management criteria to reduce the high mortality of this geriatric group.

The most common surgical emergency was Intestinal Perforation.

We would like to emphasise on detailed examination. Xray abdomen erect and ultrasonography is a must to provide an early diagnosis. Though in rural areas, unaffordability and 
ignorance for geriatric mass is a major drawback, and there is a reluctancy to do investigations. Therefore, x-ray abdomen erect and ultrasonography is sufficient for the approach.

Factors like hypoalbuminaemia, anaemia, comorbidities like DM, HTN, deranged RFTs, electrolytes and hyperglycaemia are the nidus for bad prognosis for this age.

The only way to reduce mortality is to be prompt to diagnose, immediately intervene and overcome the nidus like hypoalbuminaemia, anaemia, respiratory distress and cardiac complications.

Thus, time and treating the elements is the essence for the neglected geriatric mass to survive in cases of abdominal surgical emergencies.

\section{REFERENCES}

[1] Akinbami F, Askari R, Steinberg J, et al. Factors affecting morbidity in general surgery. Am J of Surg 2011;201(4):456-62.

[2] American College of Surgeons. National Surgical Quality Improvement Programme (ACS NSQIP). Chapter 4, ACSNQIP variables and definition. http://acsnqip.org/.

[3] Khoja HR, Garg D, Gupta M, et al. Evaluation of risk factors and outcome of surgery in elderly patients.JIndian Acad of Geriat2008;1:14-7.

[4] Sawyers JJ, Herrington JL, MulherinJLJr, et al. Acute perforated duodenal ulcer: an evolution of surgical management.ArchSurg 1975;110(5):527-30.
[5] Offner PJ, Moore EE, Biffl WL. Male gender is a risk factor for major infections after surgery. Arch Surg 1999;134(9):935-40.

[6] Golub R, Sorrento JJ Jr, Cantu R Jr, et al. Efficacy of albumin supplementation in the surgical intensive care unit: a prospective, randomized study. Crit Care Med 1994;22(4):613-9.

[7] Earley AS, Pryor JP, Kim PK, et al. An acute care surgery model improves outcomes in patients with appendicitis. Ann Surg 2006;244(4):498-504.

[8] Britt RC, Weireter LJ, Britt LD. Initial Implementation of an acute care surgery model: implications for timelines of care. J Am CollSurg 2009;209(4):421-4.

[9] Hill AC,Schecter WP, Trunkey DD. Abdominal trauma and indication of laparotomy. In:Mattox KL,Moore EE,Feliciano DV, eds. Trauma. Norwalk:Appleton \& Lange1988:p. 401.

[10] Foley RW, Harris LS, Pilcher DB. Abdominal injuries in automobile accidents: review of care of fatally injured patients. Journal of Trauma 1977;17(8):611-5.

[11] Neuman TS, Bockman MA, Moody P, et al. An autopsy study of traumatic deaths: San Diego County, 1979. The American Journal of Surgery 1982;144(6):722-7.

[12] West JG, Trunkey DD, Lim RC. Systems of trauma care: a study of two counties. Archives of Surgery 1979;114(4):455-60.

[13] Dasgupta S, Paul AK. Management of intra-abdominal injuries. J Ind Med Assoc1975;64:336. 